Motto: No internal audit without internal control, No internal control without working procedures

No working procedures without risk register

The author

\title{
IMPLEMENTING THE INTERNAL CONTROL \& FINANCIAL MANAGEMENT SYSTEM
}

\section{Ph.D. Razvan Ghita, Valahia University Târgoviste, marcel.ghita@mfinante.ro}

\begin{abstract}
The implementation of internal audit function in Romania has imposed the reorganization of the internal control system that existed within public entities. Although, commonly it would have been the other wayaround, due to the European Union's pressures it was first implemented the internal audit function in the Romanian public sector.

Nowadays, we found ourselves in a process of organization and implementation for the financial control and management system within entities from the public sector.

The article presents the internal audit function's evolution and the present (actual) stage of implementation of internal control and management system, process that began in 2005, in the Romanian public sector.
\end{abstract}

The internal auditor profession, in today's conception, it is a new profession that evolves constantly. As such, the internal audit's objectives that consisted in the examination of accounts and to provide the necessary assistance for the entity's personnel so that they could fulfill their professional obligations, in time, were completed with evaluations, analysis and advices for management, through findings and recommendations contained in the reports elaborated by the internal auditors.

During the past fifty years, internal control and, implicit, internal audit but, also, the external audit have had a rapid and continual development and profession in terms of entity's objectives, which, also, are in a continual change.

In time, internal audit has detached itself as an indispensable activity for the management, as a distinct function within the entity, with the purpose of evaluating the internal control system.

Nowadays, the managers have understood the fact that internal audit and external audit are different activities, with professional standards, methodologies and working procedures with different reporting systems, but which are completing each other.

Within an entity that doesn't have an organized internal audit, external audit must perform detailed tests to gain assurance and to lay down an opinion.

Where there is an internal audit function, external auditors start with the evaluation of risks that have been kept in view by the internal auditors and expand their samples in accordance to the necessary assurance needed for issuing their opinions.

About the audit is said, nowadays, that has became an universal function, feature attained through the fact that it is organized and because of the fact that has to be executed within every entity and at all levels. This feature has as its base the practice of internal audit activity which has the obligation to audit all the entity's functions, programs, processes and activities.

Internal audit it is a profession that has always redefined itself over the years, because of a desire to respond to the changing necessities of entities. Concerned, at first, on accounting matters, the internal audit's objectives have moved towards the evaluation of an entity's internal control system and towards tracking the major risks of an entity regarding their pre-established targets. 
The presence of internal audit at the highest level within the entity and because of the fact that it fulfils, past the assurance function regarding the functionality of the internal control system, and a consultancy function for the manager for supervising the smooth running of the entity, without the managerial decision attribute, makes a constant manifestation in the act of governance as being on the same side of general management.

The existence of a functional internal audit department within the entities confirms the transparency enforced to the managerial actions.

The preparation for Romania's accession to the European Union has imposed, between other matters, the reorganization of the internal control system within the entities, which was organized under the form of control/examination compartments or distinct inspections.

As such, the European Commission's recommendations have been oriented towards the annulment of such compartments and the integration of internal control activities within the flux of processes that are conducted within entities. The maintenance of a control or inspection compartments it can be explained just through the existence of specific activities within the respective entity and it can be justified by a suitable volume of activity. For example, in some ministries it has been maintained a general directorate for performing inspections due to the impressive volume of intimations and vindications which needed urgent responses, and by sending these matters to the executive structures for solution, would have led to the "suffocation" of their main activities.

Because of these considerations, in 2005, within the Ministry of Economics and Finances, it was set up the Central Harmonization Unit for Financial Management and Control - CHUFMC $^{1}$ besides the Central Harmonization Unit for Internal Audit - CHUIA ${ }^{2}$ - set up in 2003, both at the European Union's recommendations, for the purpose of supporting general management within the public entities in the task of defining and organizing their own internal control system.

In this way, Romania has became the only country within the European Union with two central harmonization units, respectively one for the internal control system and one for internal audit, in contradiction with the other countries that have a central authority for both components (Hungary, Bulgaria), or just one central unit for internal audit (Poland, The Baltic countries) or neither (Denmark, Sweden, Norway). We consider the situation within Romania to be a fortunate one which will contribute to the acceleration of implementing The Financial Management System and Internal Control - FMSIC -, which represents a new managerial control system within the public entities of Romania.

The main purpose for which the Central Harmonization Unit for Financial Management and Control has been set up consisted in helping the general management within public entities to define and organize the proper internal control system.

Because of these considerations, in 2005, the Central Harmonization Unit for Financial Management and Control has issued the Internal Control Code ${ }^{3}$, which comprises the internal control/management standards at the public entities for the development of managerial control systems and contains dispositions regarding the management' obligations and responsibilities for every public institution, from which we pass in review:

- the public entities directors will lay-out the necessary measures for the elaboration and development of managerial control systems on the basis of international control standards, including the written procedures for each activity;

\footnotetext{
${ }^{1}$ Government Decision no. 2.088/2004 for the modification and completion of Government Decision no. 1574/2003 regarding the organization and function of the Ministry of Public Finances and the National Agency for Financial Administration

${ }^{2}$ Law no. 672/2002 regarding public internal audit, published in the Official Gazette no. 953/2002.

3 Order of minister of public finances no. 946/2005 approving the Internal Control Code, comprising the internal management/control standards at the public entities and for the development of the managerial control systems, published in the Official Gazette no. 675/28.07.2005
} 
- the management has the obligation of identifying risks and to undertake the actions needed to maintain risks at acceptable levels;

- for the eventual needs of undertaking precise examinations or control activities, managers can set up commissions or, if the situation imposes, control/examination teams, even control compartments which can function on a permanent basis or for a temporary period of time, regarding the solution of any malfunctions or irregularities found within the entity and after the completion of the mission, the members can retake their responsibilities, according to the job description.

The principles of good practice, accepted at an international level, which compose the community aquis, have been the basis for the realization of internal control standards. At the elaboration of internal control standards has been taken into account the experience gathered by the European Commission, INTOSAI, Committee of the Sponsoring Public Entities of the Treadway Commission (U.S.A.) -COSO and Canadian Institute of Certified Accounts (Criteria of Control) CoCo. The way through which these principles are transposed in the internal control/management systems specifically for every country depends on the constitutional, legal, cultural, administrative conditions.

Internal control standards represent an important input for the cognition of general principals of good practice in the field, on the basis of which entities can establish structures for applying the financial management and internal control systems.

For implementing the proper internal control system, the entities' directors must lay-out the necessary measures for the organization and/or development of the risk register, managerial control systems of every activity, the operational work procedures, formalized on fluxes/processes/activities, bearing in mind the particularities of the legal framework and other specific elements.

Internal control standards define a minimum of mandatory rules for the management, rules that must be implemented and to follow-up their permanent operation, together with internal audit.

The purpose of these internal control standards consists of a reference system, in relation with the organization of managerial control within the entity and, also, it identifies the areas and direction that require change.

In conclusion, the organization and implementation of the internal control standards it is included in the responsibility of every entity's management and it must be founded on the standards issued by the Ministry of Economics and Finances.

Objectives, actions, responsibilities, deadlines and any other components of these specific measures will be comprised within managerial control development programs, issued at the level of every public entity. In these programs will be comprised, distinctively, actions of professional training, for persons from the management level and, also, for the persons from executive levels, and, also, the concrete way of achievement.

For the follow-up and methodological guidance and coordination regarding the proper managerial control systems, through internal decision act, the director of the public entity sets up working groups with attributions regarding the component, way of organization and function and any other elements that are establish, bearing in mind the volume and complexity of the public entity's activities.

Internal control is presents on the entity's hallways and it is manifested under the form of self-control, chain control (in terms of the process' stages) and of hierarchical control. Regarding the moment at which the control is exercised, the control can be concomitant (operational), ex-ante (feed-forward) and ex-post (feed-back).

Within the current control activities we encounter: observation, the refer note, the decision, the sanction, the planning stage, the examination, the analysis, controlling the expenses, safeguarding the assets, the disjunction of duties, reporting and follow-up.

The current control activities will have to be integrated within the executive management through their inclusion in formalized operational procedures. In this way, the proper internal control 
system, founded in every entity, has to be organized and harmonized constantly to allow the management to have the best control possible over the running of the entity as a whole, and, also, over every activity, for the purpose of achieving the established goals.

The general manager/ credit sequencer and also all the other persons that have a management position in the respective entity, are responsible for the creation and function of that particular internal control system which has to give a reasonable assurance regarding the achievement of the entity's goals.

Managerial responsibility exerted by an entity's management presumes, within the limits of internal and external restraints, to achieve the established objectives in an efficient, efficacious manner, according to the legal framework, to communicate and to respond for the lack of fulfillment regarding their managerial obligations.

Managers must not wait for somebody outside their organization to arrive and to organize the proper control system of the respective entity.

During the period of planned economy, they were accustomed with the system in which the Romanian Court of Accounts, the Ministry of Public Finances and other external control organisms came, on a regular basis, to realize background controls regarding their own activity.

Nowadays, managers must recognize their responsibility which they hold in organizing their proper internal control system, within the entities they manage and, also, recognize the responsibility that has been totally transferred to them, a fact that presumes their implication in the most efficient way of organization.

For the public sector, the role of the Ministry of Economics and Finances and/or the Romanian Court of Accounts consists in evaluating the manner in which the internal control system implemented by the management works and if it is capable of foreseeing or stopping the misusage of funds and to identify possible weak points in the transaction of the administrated funds.

In these conditions, the management must "devise" control activities which will allow it to master the risks which can appear and evolve constantly and to limit their consequences, through a flexible internal control system, which has to be decreased or developed with ease in certain areas or compartments, where the situation demands, within the entities.

The financial management and internal control system - $\mathrm{FMICS}^{4}$ - comprises the cline of internal control activities realized at the entity's level, including internal audit.

In Romania, internal audit is organized, by law, in the public sector, but it remains a constant challenge for the private sector too.

After Romania's accession at the European Union, the pre-accession funds (PHARE, ISPA and SAPARD) will become structural funds, both for public and private entities, and, as such, it will be inconceivable to be used without the follow- up and evaluation of internal auditors.

The scope of internal audit which is organized in entities consists of providing consultation for general management and to evaluate the functionality of internal control system, activities by which it can create a supplementary value for the audited entity.

An internal audit function, in order to be efficient, must be based on the internal control and management system within the entity because it represents the object of internal audit's activity. In the situation in which the internal control system within the entity it is not organized and doesn't function, accordingly to the international standards, then neither the internal audit function will be efficient.

As a consequence, the organization of internal audit activity doesn't decrease or dissolve the internal control. Contrariwise, within the context of general international principles of good practice, the control is associated with a much larger conception, being regarded as a managerial attribute/function and not just a simple examination operation.

\footnotetext{
${ }^{4}$ Financial management and control in English
} 
The optimal function of entities on the basis of an integrated internal control framework imposes the existence of an adequate control environment which can promote ethics values, is transparent, accepts the standards of good practice and establishes responsibilities in accordance with the strategies and policies approved by the upper level management.

Internal audit will achieve its goals only in the situation in which there is a well organized internal control system, formalized and, periodically, consisted of: standards and procedures, professional guides, deontological/ethical codes, which can sustain the ethics of the audit profession, bearing in mind the fact that the internal auditor has to be above any suspicions "like Caesar's wife".

Managers must understand the internal auditors' recommendations and findings, to perceive the help they are getting in mastering risks, as they appear and modify on a regular basis, and their positive attitude towards the entity.

Internal auditors and managers must be regarded as partners and not as adversaries, both having the same goals, from which we can name the efficiency in management's act for achieving the proposed targets, in performance conditions.

Internal audit is considered to be the last level of the entity's internal control system, which doesn't affect activities like inspections and control, but evaluates the internal control system and provides for the general management a point of view regarding its functionality within the entity.

Conclusively, internal audit it's a part of the internal control system of a public entity, but it is something else, respectively it represents that component which evaluates, follow-up and supervises the function of internal control and management system, through follow-up procedures for the way in which internal auditors' recommendations and findings will be implemented. 